\title{
Breath Biomarkers and the Acute Respiratory Distress Syndrome
}

\author{
Katrina M. Crader, Jonathan J. D. Repine and John E. Repine*
}

Webb-Waring Center, University of Colorado Denver, V20, Mail Stop C322, 12850 East Montview Blvd. Aurora, CO 80045 USA

\begin{abstract}
Because pharmacologic treatment of patients with the established Acute Respiratory Distress Syndrome (ARDS) has not been successful, the emphasis on discovering biomarkers that predict ARDS development in at-risk individuals is being rekindled so that ways of preventing ARDS can be advanced and tested. However, the low incidence of ARDS in at-risk individuals, the variable time between becoming at risk and developing ARDS, and the varying incidence of ARDS following different predisposing conditions makes finding clinically-useful ARDS predicting biomarkers challenging. Ideally, biomarkers reflecting ARDS development will be obtainable non-invasively and repeatedly and provide sensitive, specific, accurate and real time results. Biomarkers will also likely need to mirror key events in the pathogenesis of ARDS and meaningfully reflect the effect of therapies on ARDS development. At the moment, analysis of potential biomarkers in breath samples offers an intriguing way of addressing these objectives. A number of ARDS implicated molecules (e.g. hydrogen peroxide, nitric oxide, lipid peroxidation byproducts, cytokeratins) are measurable in breath or breath condensates from ARDS patients. Moreover, powerful new approaches (e.g. proton transfer reaction mass spectrometry, carbon nanotubes analyses using aptamer based multiplexed proteomic technology and cavity-enhanced frequency comb spectroscopy) are emerging that may provide biomarkers that could generate insight regarding the responsible mechanisms for ARDS, monitor ARDS development, enable testing of new ARDS interventions, and guide treating and preventing ARDS.
\end{abstract}

Keywords: Inflammation; Lung; Antioxidant; Biomarkers; Breath; ARDS; ALI

Abbreviations: ARDS: Acute Respiratory Distress Syndrome; ALI: Acute Lung Injury; $\mathrm{H}_{2} \mathrm{O}_{2}$ : Hydrogen Peroxide; NO: Nitric Oxide; $\mathrm{PGE}_{1}$ : Prostaglandin $\mathrm{E}_{1}$; MDA: Malondialdehyde; MOF: Multiple Organ Failure; AIDS: Acquired Immune Deficiency Syndrome; NAC: N-acetylcysteine; NADPH oxidase: Nicotinamide Adenine Dinucleotide Phosphatase oxidase; IL-1: Interleukin 1; IL-8: Interleukin 8; TNFa: Tumor necrosis factora; PUFA: Polyunsaturated Free radicals; 8-iso-PGF ${ }_{2 a}$ : 8-iso-prostaglandin $\mathrm{F}_{2 \mathrm{a}}$; GC: Gas Chromatography; MS: Mass Spectroscopy; IMS: Ion-mobility Spectroscopy; TD: Thermal Desorption; PTR: Proton Transfer Reaction; P/F: $\mathrm{PaO}_{2} /$ fraction of inspired oxygenation; DNA: deoxyribonucleic Acid

\section{Introduction}

Interest in finding biomarkers that predict the development and potentially provide the opportunity of preventing acute respiratory distress syndrome (ARDS - used herein to include ALI, ARDS and early forms of acute inflammatory lung injury) is being rekindled [1]. One attractive possibility is the analysis of breath and breath condensate products. Evaluating breath biomarkers that reflect ARDS development may provide a useful method alone and/or in conjunction with other approaches in accomplishing the objectives of learning more about the pathogenesis, treatment and prevention of ARDS [2-4]. Some pioneering work has already been done in the field of breath analysis. For example, Phillips identified three thousand different compounds in the breath of a normal person [5]. Because of the intense inflammatory, oxidative and other reactions occurring in the lungs of patients as they develop ARDS, it is likely that breath analysis could provide useful new information.

In the present review, we identify molecules that have been measured in the breath and breath condensates of patients with ARDS and consider their potential as ARDS biomarkers. A number of these molecules, most notably hydrogen peroxide, have also been measured in the breath or breath condensates of animal models of ARDS but this review focuses only on findings in human subjects [6]. Our review will also not describe some of the important considerations that have been raised in prior articles including potential issues related to exhaled breath sample collection $[7,8]$, low concentration/dilution effects [913], contamination by water and other substances [14,15], processing and storage issues [16], "head-to head" comparisons of breath and breath condensate findings to bronchoalveolar lavage findings [17,18], ensuring samples are only from the lung [14,15], validation $[19,20]$, instability [21], reproducibility [22-24] and analysis [25,26].

\section{ARDS}

ARDS, the most severe form of Acute Lung Injury (ALI), remains a formidable medical problem [27]. ARDS has a high mortality approaching $40 \%$ in many studies [28,29]. ARDS kills approximately 75,000 Americans yearly; by some estimates, more than breast cancer and AIDS combined [28,29]. ARDS is characterized by the rapid onset of a diffuse non-cardiogenic edematous lung injury that produces severe hypoxemia. For largely unknown reasons, ARDS follows a wide variety of predisposing conditions including trauma, infection, pancreatitis, blood transfusions, and aspiration [2,3]. ARDS often predisposes to multiple organ failure (MOF) and this devastating complication along with ARDS creates considerable mortality and expense [30]. Even survivors of ARDS have appreciable residual disabilities including lung, musculoskeletal, and mental abnormalities $[31,32]$. Despite laudable advances in supportive care and judicious use of mechanical ventilation, the syndrome remains lethal and there is no pharmacologic treatment [33].

*Corresponding author: John E. Repine, MD, Webb-Waring Center, University of Colorado Denver, V20, Mail Stop C322, 12850 East Montview Blvd. Aurora, CO 80045 USA, Tel: 303-724-4783; E-mail: john.repine@ucdenver.edu

Received November 08, 2011; Accepted December 30, 2011; Published January 01,2012

Citation: Crader KM, Repine JJD, Repine JE (2012) Breath Biomarkers and the Acute Respiratory Distress Syndrome. J Pulmonar Respirat Med 2:111. doi:10.4172/2161-105X.1000111

Copyright: (C) 2012 Crader KM, et al. This is an open-access article distributed under the terms of the Creative Commons Attribution License, which permits unrestricted use, distribution, and reproduction in any medium, provided the original author and source are credited. 


\section{Lack of Pharmacologic Success in Treating Established ARDS}

Numerous attempts with pharmacologic agents have been universally unsuccessful in reducing the high mortality of established ARDS [33]. The list of ineffective therapeutics encompasses a variety of agents chosen for their potential in limiting different pathologic features that appear to contribute to ARDS. The unsuccessful candidates include methylprednisolone, lysofylline, prostaglandin $\mathrm{E}_{1}, \mathrm{~N}$-acetylcysteine, ketoconazole, nitric oxide, and surfactant [34]. Although not effective in increasing survival, some of these interventions improved physiologic and/or biochemical abnormalities associated with ARDS and may hold potential if given earlier to at-risk patients who are in the process of developing ARDS [34]. For example, nitric oxide, surfactant, methylprednisolone and prostaglandin $\mathrm{E}_{1}$ improved oxygenation in patients with established ARDS. N-acetylcysteine (NAC) prevented glutathione depletion [35] and surfactant reduced lung lavage IL-6 levels - again without improving mortality in patients with established ARDS [34].

\section{Emphasis on Preventing ARDS}

Disappointment in treating established ARDS has fueled a lack of enthusiasm on many fronts for attempting to treat established ARDS. The disillusionment is substantial since investigators have repeatedly found that agents that work effectively in animal models of ARDS do not produce the same results in full-scale clinical trials in patients with established ARDS [36,37]. However, many times, these interventions were given just before the ARDS inciting insult was administered to the animal $[36,37]$. The discouraging track record in treating patients with established ARDS has also engendered skepticism in pharmaceutical companies, Wall Street and Venture Capital Investors. These pivotal entities must now more carefully weigh the potential risks and substantial expense involved in developing interventions for treating established ARDS - not the least of which is the multi-million dollar definitive phase III trial that will likely need 1000 patients or more to establish efficacy $[1,38]$. Indeed, by the time the diagnosis of ARDS is fully established and patients meet definitive entry criteria for most clinical trials, nearly all ARDS patients are extremely ill and many detrimental processes are in full swing. The multiple redundant, likely synergizing, inflammatory, oxidative stress and other responses that contribute to ARDS do not obviously lend themselves to a simple rescue intervention. While all efforts at discovering ways to treat established ARDS have not been abandoned, emphasis on preventing ARDS development rather than treating established ARDS is an attractive emerging perspective [1]. This rationale has significant merit [27].

While theoretically appealing, the proposition of preventing ARDS development must nonetheless overcome many obstacles. A primary concern is that many at-risk individuals have conditions like trauma or infection that predispose to ARDS, but only a relatively small number of presently indefinable at-risk individuals develop the syndrome [39]. Using a sophisticated cleverly constructed clinical scoring system, Gajic and his colleagues were only able to predict ARDS development in atrisk individuals at a rate of approximately $18 \%$ [39]. Clearly, if we treat everyone at-risk, we will treat many individuals who are not destined to develop ARDS. This strategy means that we will unnecessarily expose many at-risk individuals - many of whom like many victims of trauma are in completely good health just beforehand - to the obvious expense and potential risk of the therapy. The latter approach is also complicated because many diverse disorders predispose to ARDS and because ARDS does not develop in any fixed time period in at-risk individuals. In addition, many patients would need to be studied in clinical trials to show the efficacy of an intervention when the primary endpoint is ARDS prevention and no subject enriching biomarkers or other limiting directives are employed [1].

\section{Need for Biomarkers for Predicting ARDS}

The strategy of preventing ARDS with efficiency is being addressed by a search for biomarkers that can predict ARDS development in at-risk individuals. Appropriate ARDS predictive biomarkers will not only facilitate earlier treatment, but also increase the odds of preventing ARDS in someone who has a greater chance of developing it. The complexity of ARDS and its variable development in different individuals makes this quite difficult and indicates that a panel of biomarkers, rather than a single biomarker, will be needed to predict ARDS [1]. Since we do not know exactly when ARDS will develop in any individual, the ideal biomarker will need to be obtainable repeatedly, non-invasively and provide real-time information. Most likely, the approach will require frequent measurements of significant biomarker changes that occur in the same individual over time. This concern effectively makes analysis of lung lavage and lung tissue problematic since they are difficult to perform and repeat in criticallyill individuals [40]. This requirement also raises a similar, albeit to a lesser degree, concern for using blood and urine analyses. For this reason alone, the potential for evaluating exhaled breath samples has appeal. Breath samples coming directly from the lung are theoretically relatively easy to collect non-invasively and repeatedly, especially in intubated patients. If nothing else, the search for pragmatic biomarkers will provide additional insights regarding the mechanisms contributing to ARDS and lead to new therapeutic strategies.

\section{Known Breath Biomarkers in ARDS}

The initial pathogenesis of ARDS remains largely centered on inflammatory cytokine elaboration, neutrophil recruitment and activation and oxidative stress in the lung. This myriad of related inflammatory and oxidative stress reactions occur in the lung could generate molecules that could be detectable by analysis of breath or breath condensates. Not surprisingly, inflammatory, oxidative stress and nitrosative stress related molecules are the most frequently measured targets explored in the breath and breath condensate molecules of ARDS patients.

\section{Cytokines}

Despite the importance of cytokines in the early development of ARDS, only one report has shown increased interleukin and tumor necrosis factor levels in the exhaled breath of patients with acute lung injury compared to healthy volunteer control subjects [41].

\section{Hydrogen peroxide}

One of the most fascinating molecules measured in exhaled breath condensates is hydrogen peroxide [42], a reactive oxygen species likely formed by the dismutation of superoxide anion made by NADPH oxidase, xanthine oxidoreductase, mitochondrial or other processes in phagocytic and other cells [1]. $\mathrm{H}_{2} \mathrm{O}_{2}$ is important since its reaction with superoxide anion in the presence of ferrous iron produces the highly toxic hydroxyl radical which is one of the most potent oxidants known [43]. In addition, reaction of $\mathrm{H}_{2} \mathrm{O}_{2}$ and the neutrophil constituent myeloperoxidase with a halide generates hypochlorous acid that can cause appreciable cell damage [44]. Baldwin and his colleagues found increased breath condensate $\mathrm{H}_{2} \mathrm{O}_{2}$ levels $(1.68+/-0.35 \mu \mathrm{mol} / \mathrm{l})$ measured on the day of diagnosis in ARDS patients compared to breath $\mathrm{H}_{2} \mathrm{O}_{2}$ condensate levels $(0.34+/-0.08 \mu \mathrm{mol} / \mathrm{l})$ in comparable 
patients who did not develop ARDS [42]. Increased exhalation of $\mathrm{H}_{2} \mathrm{O}_{2}$ was associated with an increased turnover of neutrophil lysozyme implicating the possible role of neutrophils in the production of $\mathrm{H}_{2} \mathrm{O}_{2}$, but the exact source of exhaled $\mathrm{H}_{2} \mathrm{O}_{2}$ remains unproven. Interestingly, the breath $\mathrm{H}_{2} \mathrm{O}_{2}$ levels of patients with pneumonia were lower than in ARDS patients and breath $\mathrm{H}_{2} \mathrm{O}_{2}$ levels did not correlate with inspired oxygen concentrations [42]. Significantly, serial breath condensate $\mathrm{H}_{2} \mathrm{O}_{2}$ levels fluctuated in accordance with the clinical status of the patients. The central importance of oxidative stress and $\mathrm{H}_{2} \mathrm{O}_{2}$ was underscored by another investigation in which patients with acute respiratory failure exhibited higher breath $\mathrm{H}_{2} \mathrm{O}_{2}$ condensate concentrations [45]. Sznajder and colleagues found that patients with respiratory failure and lung infiltrates but not ARDS per se, exhaled high concentrations of $\mathrm{H}_{2} \mathrm{O}_{2}$ but ARDS patients still had the highest median breath $\mathrm{H}_{2} \mathrm{O}_{2}$ concentrations [46]. Their observation emphasizes the inherent challenges in distinguishing at-risk individuals who will or will not subsequently develop ARDS [1]. Similarly, patients with acute respiratory failure exhaled higher $\mathrm{H}_{2} \mathrm{O}_{2}$ concentrations than control patients (median $95 \mathrm{nmol} / \mathrm{l}$, range $76-144 \mathrm{nmol} / \mathrm{l}$ ) with the highest median value in ARDS patients (552 nmol/l, range 154-893 nmol/l) [47] Notwithstanding, spectrophotometric analysis of $\mathrm{H}_{2} \mathrm{O}_{2}$ levels in breath condensate may lack specificity due to variable levels of contaminants in the samples that potentially lead to false positives [48] - an issue that can likely be addressed using other measurement approaches [49-51] and, when possible, by adding catalase to provide a catalase-inhibitable specific assessment of $\mathrm{H}_{2} \mathrm{O}_{2}$.

\section{Nitric oxide}

Although treatment with nitric oxide did not decrease the mortality of ARDS patients [34], there is still interest in using exhaled nitric oxide as a biomarker [52-54]. Exhaled breath condensate nitrite levels increased and correlated with reduced tidal volume and lung injury, but not inflammation reflected by IL- 8 and IL-6 levels in serum samples, in ARDS patients receiving mechanical ventilation [55]. Nitrite likely reflects the production of nitric oxide by phagocytes or other lung cells and, accordingly, it is another potential biomarker that could reflect lung inflammation and oxidative stress. Moreover, exhaled nitrite levels correlated with lung distension and related lung injury. The importance of nitrate or nitric oxide exhalation resides in its ability to reflect nitrosative reactions, such as the production of peroxynitrite, following reaction of nitric oxide with superoxide anion--a process that might account for nitrotyrosine increases that occur and reflect lung inflammation and injury in ARDS patients [56]. Nitric oxide as measured in mixed expired air samples has also been proposed as a possible biomarker for detecting early acute lung injury in patients requiring coronary artery bypass grafting [57]. However, another study reported that exhaled nitric oxide levels of ARDS patients ( $1.13 \pm 0.36$ parts/billion) were lower than in a control group of ventilated subjects (5.5 \pm 0.8 parts/billion) [58].

\section{Acidification}

Acidification of the exhaled breath condensate occurs in patients with acute lung injury and correlates with pro-inflammatory cytokine concentrations locally but not systemically $[59,60]$. Exhaled breath condensate $\mathrm{pH}$ was decreased in ventilated patients $(5.85 \pm 0.32)$ compared to volunteers $(7.46 \pm 0.48)$. Exhaled breath condensate $\mathrm{pH}$ correlated with exhaled breath condensate IL-6, IL-8, ammonia and lactate levels but not serum IL-6 and IL-8 levels. Measuring acidification does not require extensive instrumentation and can be repeated easily. Exhaled breath condensate $\mathrm{pH}$ decreases also develop following lung resection and one lung ventilation [61] and in mechanically-ventilated, brain-injured patients without acute lung injury or sepsis compared to healthy and brain injured control subjects [62]. Although the exact physiologic significance of this abnormality is unknown, breath $\mathrm{pH}$ still may prove useful as a biomarker especially if its cause can be discerned since neurogenic inflammation is triggered by airway or esophageal acidification, innate immune cells are affected by acidity, and there are pathways by which the acquired immune system also can be activated by the chemistry of an acidic airway [63].

\section{Lipid peroxidation byproducts}

Lipid peroxidation is the result of the oxidative degradation of lipids. It occurs when free radicals attach themselves to electrons in cell membranes and cell damage results. This process then propagates via a free radical chain reaction mechanism. Polyunsaturated fatty acids (PUFA's) are most commonly affected because of the methylene groups that separate the multiple double bonds. The well established products of PUFA include aldehydes, ethane, pentane, malondialdehyde, acrolein, hydroxynonenal, crotonaldehyde and neuroprostanes. Methylene groups contain reactive hydrogens. The radical reaction consists of three major steps: initiation, propagation, and termination. Carpenter and his colleagues found that the mean level of 8-iso- $\mathrm{PGF}_{2}$ in the exhaled breath condensate in patients with ALI/ARDS $(87 \pm 28$ $\mathrm{pg} / \mathrm{ml})$ was higher than the mean of the normal group $(7 \pm 4 \mathrm{pg} / \mathrm{ml})$ [64]. Breath pentane concentrations were increased in ARDS patients compared to subjects with head injury and subjects at-risk for ARDS Pentane exhalation increased with increasing inflammatory status and generally were associated with malondialdehyde and thiobarbituric acid increases in plasma [65]. In the same study, breath isoprene levels were lower in ARDS patients [65]. The latter change was also found in two additional evaluations of ARDS patients $[15,66]$.

\section{Volatile organic compounds}

Volatile organic compounds (VOCs) are derived from saturated hydrocarbons (including PUFA's), unsaturated hydrocarbons, oxygen-containing compounds, sulphur-containing compounds, and nitrogen-containing compounds. Hydrocarbons such as ethane, pentane and isoprene; oxygen-containing compounds like acetone, acetaldehyde, methanol, ethanol, and 2-propanol; sulphur-containing compounds such as dimethylsulfide, methyl, and ethyl mercaptanes; and carbon disulfide and nitrogen-containing substances such as ammonia and dimethyl/trimethylamine are also considered in some reports as VOC's. VOC's can be generated anywhere systemically and then via the blood be exhaled through the lung [67]. VOCs measured by integrative analysis of 60 second samples of exhaled air from the ventilatory circuit closed to the endotrachial tube with an electronic nose (eNose) revealed that the breath prints of 17 patients with ALI/ ARDS were significantly $(p<0.001)$ different from 9 control ventilated neurosurgery patients not matching any criterion for acute lung injury.

\section{Cytokeratins}

Cytokeratins - indicators of lung epithelial damage- were increased in the breath condensate of individuals with ARDS compared to samples from healthy control subjects [68].

\section{Response of Breath Biomarkers to Pharmacologic Intervention}

While the capacity of breath biomarkers to reflect and perhaps predict ARDS development is of paramount importance, an additional benefit would be achieved if biomarkers change informatively in response to a therapy that has a beneficial effect clinically [69]. Ideally, a 
treatment that successfully reduces responses that contribute to ARDS would be accompanied by a corresponding change in an appropriate biomarker or biomarkers. Conversely, treatment with an intervention that does not decrease a mechanistically linked biomarker might be discontinued in favor of another therapy. Studies have begun to address this possibility but without success. Corticosteroid treatment decreased breath $\mathrm{H}_{2} \mathrm{O}_{2}$ levels but not mortality in ARDS patients [47]. Despite its ability to down regulate DM11/CD18 neutrophil receptor, liposomal $\mathrm{PGE}_{1}$ treatment improved the $\mathrm{P} / \mathrm{F}$ ratio and decreased the white blood cell count but did not reduce exhaled $\mathrm{H}_{2} \mathrm{O}_{2}$ levels [70]. Roca and associates examined the exhaled breath condensate collected from six patients with acute lung injury before and 30 minutes after administration of inhaled salbutamol [71]. Salbutamol increased breath condensate $\mathrm{pH}$ and in a trend way decreased nitrosactive species and 8-isoprostane levels, but not leukotriene $\mathrm{B}_{4}$, concentrations [71]. $\mathrm{N}$-acetylcysteine (NAC) and rutin treatment decreased expired ethane concentrations in ARDS patients [72].

\section{Breath Biomarkers and ARDS-State of the Art}

\section{Ideal breath biomarker characteristics}

Molecules have been indentified in breath samples that may have potential as biomarkers for predicting and monitoring the development of ARDS but none have been fully developed and tested formally for their usefulness in practice. Likewise, no other biomarker candidates from blood, urine or other sources are currently used routinely as ARDS biomarkers. The reasons for the lack of adoption of these existing possibilities are unclear, but may reflect that none of these molecules meet enough of the desired characteristics for being a practical biomarker for use in clinical settings. The characteristics of an ideal biomarker for use in ARDS patients are extensive (Table 1). Since the optimal biomarker should reflect some key, hopefully early, contributor to the pathogenesis leading to ARDS development, the initial focus will probably be directed to finding inflammation, oxidative stress and related factors that are frequently implicated in the early development of ARDS [1].

\section{ARDS breath measuring technologies}

A number of techniques are available for analyzing biomarkers in ARDS. The approaches include electronic noses, metabolomics, gas chromatography/mass spectrometry (GC-MS), proton transfer reaction mass spectrometry (PTR-MS), carbon nanotubes, proteomics and cavity-enhanced frequency comb mid-infrared spectrometry.

Electronic noses: An electronic nose detects unique chemical signatures by reproducing the sensitivity of the human nose. They are used extensively in breathalyzers and for assessing lung cancer, halitosis, solvent exposure, metabolic products, respiratory infections, asthma, ketosis, vaginal inflammation, gastritis, fructose malabsorption, and peptic ulcers [73]. However, these devices are designed to measure various volatile organic compounds and, consequently, have difficulty distinguishing and accurately measuring concentrations of individual molecules. Electronic nose systems have the benefit of being easy to miniaturize, commercialize, and useful for providing immediate feedback.

Metabolomics: This newly emphasized approach assesses changes in the proteome, transcriptome or genome as reflected by alterations in metabolite concentrations in biological fluids, gases and tissues $[74,75]$. This technology has clinical appeal for testing blood and breath products. Metabolomics identified biomarkers may be indicators of systemic reactions rather than just pulmonary changes but are not yet amenable for generating information rapidly for clinical decision making [76].

Gas chromatography/mass spectrometry: Gas Chromatography (GC) and Mass Spectrometry (MS) can independently and simultaneously detect volatile organic compounds [77]. GC provides high separation efficiency and MS provides high identification capability. This combination makes gas chromatography-mass spectroscopy (GCMS) an excellent tool for measuring small quantities of volatile organic compounds in human breath. The main limitation of GC-MS is the long turnaround time necessary to collect and analyze the samples. If necessary, samples that are solid or liquid at room temperature can be converted into a gaseous state by thermal desorption. This combination technology is known as TD-GC-MS [78]. Another technology - ion mobility spectrometry - separates ions according to their mobilities. Ion-mobility spectrometry can be combined with gas chromatography (IMS-GC) or mass spectrometry (IMS-MS). One can also use protontransfer-reaction to ionize the molecules prior to mass spectrometry analysis (PTR-MS). PTR-MS has the advantage of being very quick and cost-effective but it does not detect many compounds.

Proton-transfer-reaction mass spectrometry: PTR-MS basically employs $\mathrm{H}_{3} \mathrm{O}+$ as the ionizing agent in a chemical ionization $[79,80]$. The advantage of using $\mathrm{H}_{3} \mathrm{O}+$ as the primary ion lies in its nondissociative proton transfer reaction with most volatile organic compounds, whereas it does not react with any natural air components. Compared to conventional mass spectroscopy, the non-dissociative character of the proton transfer reaction leads to less complex spectra and no previous separation of the sample compounds is required. PTRMS is a very fast, powerful online monitoring tool for obtaining realtime data with a detection limit of a few parts per trillion.

Carbon nanotubes: Carbon nanotubes provide sensitive and selective responses to vaporous analytes. They are unresponsive to water vapors because they already have water molecules tightly bound to the phosphate groups on the DNA oligomers. This feature provides a unique advantage when trying to locate unique biomarkers because they do overlap with the $\mathrm{H}_{2} \mathrm{O}$ signature and $\mathrm{H}_{2} \mathrm{O}_{2}$ is a major constituent in exhaled breath samples. DNA oligomer sensors can be modified to recognize any DNA signature so in the future that they can "smell" viral proteins signatures and also "taste" various substances. Carbon

Characteristics of an Ideal ARDS Breath Biomarker

* Reflects meaningful clinical changes in real-time that occur during ARDS development irrespective of the predisposing condition

* Discriminates ARDS from other inflammatory lung conditions

* Provides independent high-probability information about ARDS risk and/or prognosis

* Obtainable non-invasively, repeatedly, easily and inexpensively

* Responds appropriately to therapies that reduce ARDS

* Generates trend analysis so each individual can be used as his own control

* Synergizes with other ARDS biomarkers and ARDS defining criteria

* Suitable for automated bedside analysis

Table1: Characteristics of an Ideal ARDS Breath Biomarker. 


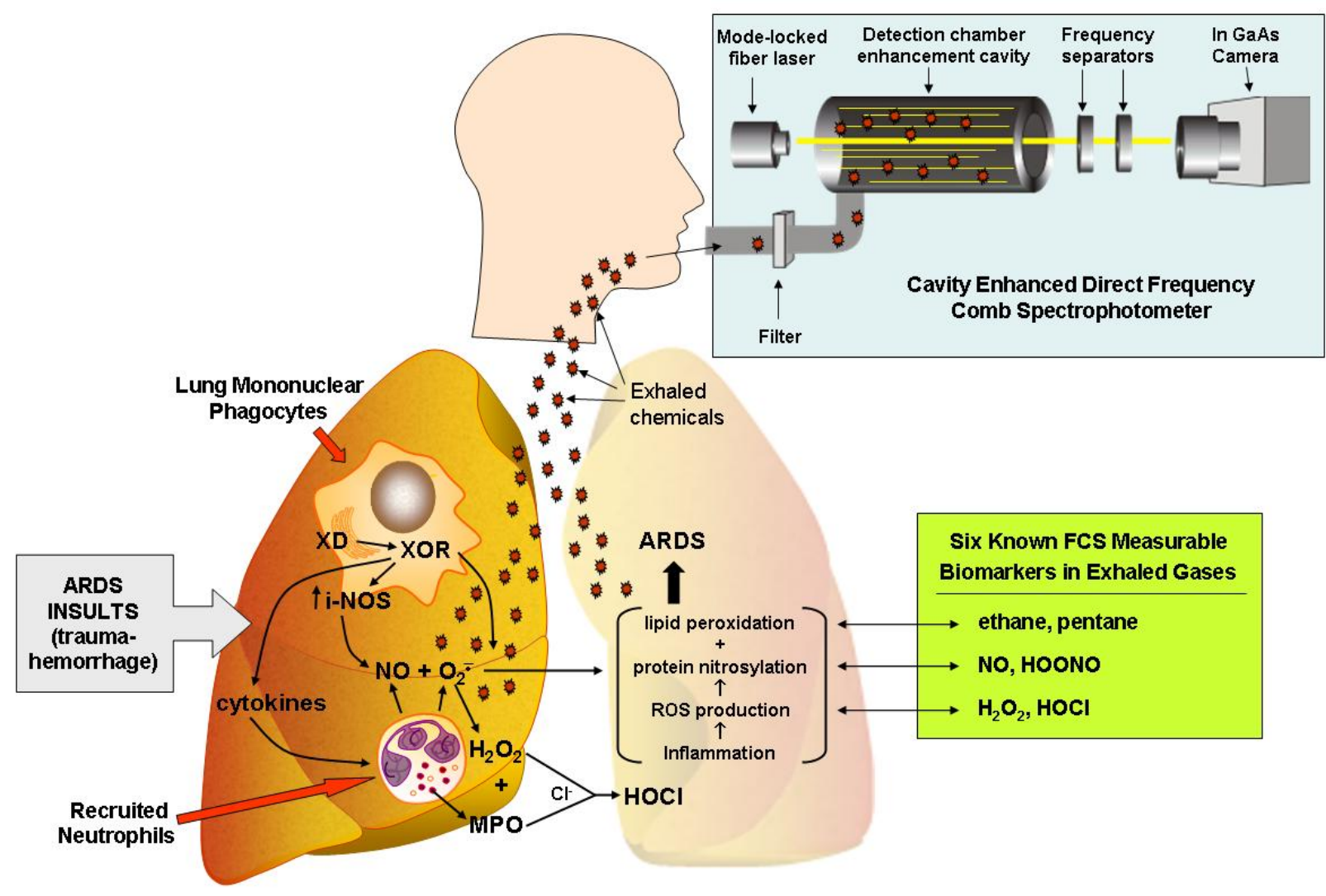

Figure 1: Schematic diagram of inflammatory and oxidative stress reactions in lungs of ARDS patient as measured by frequency comb spectroscopy analysis of exhaled breath.

nanotubes have already been used to develop a "Nano NOSE" which has great promise in distinguishing various organic diseases [81].

Proteomics: Analysis of proteins in breath condensates is possible and may be efficient using SomaLogic aptamer-based multiplexed proteomic approaches that can measure many proteins in a small sample $[82,83]$. This new approach can simultaneously measure 800 or more proteins with an average detection limit of $1 \mathrm{pM}$ and a $5 \%$ average coefficient of variation $[82,83]$. Depending on the concentration of proteins in breath condensates, this comprehensive approach may be a versatile tool which complements measurements made using metabolomics and other approaches $[82,83]$.

Cavity-enhanced frequency comb mid-infrared spectroscopy: The main benefit of mid-infrared spectroscopy is its ability to detect volatile compounds in a massively parallel fashion in seconds (Figure 1). Potentially, this approach could provide instant feedback and simultaneous recognition of multiple breath metabolites in intensive care units. Cavity enhancement techniques also permit highly sensitive detection at the level of parts per billion or more. The unique absorption spectrum also allows accurate identification and concentration measurements of a single molecule in the presence of many other molecules [84]. Frequency comb spectroscopy combines many attributes into one platform: broad spectral bandwidth, high spectral resolution, precise frequency calibration, and ultra high detection sensitivity. This platform consists of an optical frequency comb interacting with a high-finesse optical cavity. The optical frequency comb is under a very intricate level of scrutiny and precision that allows coupling of the individual comb components with their resonant modes of the cavity. Because the cavity allows the molecules to remain in the detector for a long time, the interaction between the light field and intracavity matter are increased. This increases the sensitivity of the measurement of optical losses by a factor that is directly relatable to the finesse of the cavity. The entire spectral bandwidth of the frequency comb which is approximately $10 \%$ of the actual optical frequency is examined because of the use of low dispersion mirrors. Spectral resolution of the light from the cavity creates multiple detection channels with a range of hundreds of kilohertz to several gigahertz. The femtosecond enhancement of the cavity provides for a wide bandwidth and real-time detection.

\section{Overview and Future Directions}

New strategies are needed for treating and preventing ARDS. Advances in this area will likely depend on the use of biomarkers to facilitate and guide early and more specific treatment. A number of approaches for assessing biomarkers in breath and breath condensates have been proposed but none used so far. Numerous compounds that have been measured in exhaled breath or breath condensate samples of human subjects but have not been rigorously measured to determine if they are abnormal in patients with ARDS. A partial list includes ethane [85], pentane [85], acetone [86], butane dimethylsulfide [86], isoprene [86], hexane [86], isoflurane [87], malondialdehyde [88], pro-oxidant iron [89], urea [90], surfactant protein A [91], antioxidant capacity [92], IL-1 $\alpha$ and TNFa [93], lactate [94,95], carbon monoxide [96-99], glutathione [100], ammonia [101], cysteinyl- 
leukotrienes [102], adenosine [102], 4-hydroxy-2-nonenal [100] and sodium and chloride [103] There are also reports that bacteria [104], viruses [105] and particles [106] are measurable in exhaled breath and breath condensates. Many of these substances might be relevant to the development of ARDS. For example, cytokines are increased in the lung $[107,108]$, glutathione levels are decreased in the blood [35], uncomplexed ferrous iron could facilitate the formation of the highly-toxic hydroxyl radical $[43,109]$, lactate might reflect the altered metabolic state or an increased exercise of breathing $[43,109]$ of ARDS patients. Nonetheless, the potential for using analysis of breath biomarkers is substantial since they might provide a non-invasive way of directly and repeatedly analyzing inflammatory, oxidative stress, and other processes that contribute to ARDS development.

Breath biomarkers might also help assess the effectiveness of interventions. For example, largely based on the lack of effect of omega-3 fatty acids on biomarkers of pulmonary and systemic inflammation in a phase II study of acute lung injury, the authors concluded that the results did not support conducting a larger clinical trial [110]. One might foresee that the treatment of ARDS could be individualized using breath and other biomarkers as a way to adjust the dose as well as guiding the starting and stopping therapy $[69,111]$. Consequently, ARDS treatment might differ in different individuals and at different times in the same patient during the development and course of ARDS. Considerable benefit could accrue in matching a therapy to a surrogate biomarker and a related clinical response. Moreover, the development of effective ARDS therapies is more likely to prosper as they become more customized and linked with key aspects of the pathophysiology of the syndrome. Perhaps stopping therapy sooner will facilitate important repair mechanisms that can help patients survive ARDS and have less sequelae thereafter.

The challenge will be finding the best biomarker or battery of biomarkers that correlate well with the fundamental disease mechanisms. The validity of the battery approach has already been demonstrated by Fremont and his associates who found that a panel of 7 plasma biomarkers provided the best insight into the importance of alveolar epithelial injury in early acute lung injury [112]. Additional advances will include reducing the necessary sample volume and potentially separating molecules of interest from other molecules including water [113]. Some breath measurements may require simultaneous analysis of blood levels of the same substance to achieve meaningful significance [87].

Biomarkers must be measurable in real time to optimally reflect the dynamic state of these critically ill patients. None of these approaches discussed herein will likely be the final instrumentation that provides a practical way to assess biomarkers in seriously ill individuals who undergo rapid changes in their condition. However, as more and more individuals are evaluated using these and other techniques, biomarkers will hopefully be identified that have general value and that are suitable for automated sampling and analyses [113]. Subsequently, new simplified bedside instruments will be developed that provide the careful monitoring needed by these critically-ill individuals, the ability to distinguish patients with different forms of lung inflammation $[114,115]$, and a way to better guide treatment and prevention. Developing breath biomarker analysis offers a way to help save the lives and reduce the disability of individuals afflicted with ARDS.

\section{Conclusion}

The possibility of measuring breath biomarkers holds potential to improve the understanding, diagnosis, treatment and prevention of ALI/ARDS. Once a suitable biomarker or panel of biomarkers that can be measured repeatedly, accurately and easily is identified, sequential evaluations of ALI/ARDS patients can be done and the findings carefully correlated with important clinical findings including outcome and response to treatment.

\section{References}

1. Connelly KG, Repine JE (1997) Markers for predicting the development of acute respiratory distress syndrome. Annu Rev Med 48: 429-445.

2. Cross LJ, Matthay MA (2011) Biomarkers in acute lung injury: insights into the pathogenesis of acute lung injury. Crit Care Clin 27: 355-377.

3. Barnett N, Ware LB (2011) Biomarkers in acute lung injury--marking forward progress. Crit Care Clin 27: 661-683.

4. Kuebler WM (2011) Biomarkers of acute respiratory distress syndrome: Do good things lie nearby? Crit Care Med 39: 207-209.

5. Phillips M, Gleeson K, Hughes JM, Greenberg J, Cataneo RN, et al. (1999) Volatile organic compounds in breath as markers of lung cancer: a crosssectional study. Lancet 353: 1930-1933

6. Leff JA, Baer JW, Bodman ME, Kirkman JM, Shanley PF, et al. (1994) Interleukin-1-induced lung neutrophil accumulation and oxygen metabolitemediated lung leak in rats. Am J Physiol 266: L2-8.

7. Grob NM, Aytekin M, Dweik RA (2008) Biomarkers in exhaled breath condensate: a review of collection, processing and analysis. J Breath Res 2 037004.

8. Horvath I, Hunt J, Barnes PJ, Alving K, Antczak A, et al. (2005) Exhaled breath condensate: methodological recommendations and unresolved questions. Eur Respir J 26: 523-548.

9. Buszewski B, Kesy M, Ligor T, Amann A (2007) Human exhaled air analytics: biomarkers of diseases. Biomed Chromatogr 21: 553-566.

10. Effros RM, Dunning MB 3rd, Biller J, Shaker R (2004) The promise and perils of exhaled breath condensates. Am J Physiol Lung Cell Mol Physiol 287: L10731080.

11. Schubert JK, Geiger K (1999) Importance and perspectives of breath analysis Anasthesiol Intensivmed Notfallmed Schmerzther 34: 391-395.

12. Hunt J (2007) Exhaled breath condensate: an overview. Immunol Allergy Clin North Am 27: 587-596.

13. Effros RM, Biller J, Foss B, Hoagland K, Dunning MB, et al. (2003) A simple method for estimating respiratory solute dilution in exhaled breath condensates. Am J Respir Crit Care Med 168: 1500-1505

14. Gaber F, Acevedo F, Delin I, Sundblad BM, Palmberg L, et al. (2006) Saliva is one likely source of leukotriene B4 in exhaled breath condensate. Eur Respir J 28: 1229-1235.

15. Schubert JK, Muller WP, Benzing A, Geiger K (1998) Application of a new method for analysis of exhaled gas in critically ill patients. Intensive Care Med 24: 415-421.

16. Ohanian AS, Zimmerman J, Debley JS (2010) Effects of sample processing, time and storage condition on cysteinyl leukotrienes in exhaled breath condensate. J Breath Res 4: 046002.

17. Ono E, Mita H, Taniguchi M, Higashi N, Tsuburai T, et al. (2008) Comparison of cysteinyl leukotriene concentrations between exhaled breath condensate and bronchoalveolar lavage fluid. Clin Exp Allergy 38: 1866-1874

18. Jackson AS, Sandrini A, Campbell C, Chow S, Thomas PS, et al. (2007) Comparison of biomarkers in exhaled breath condensate and bronchoalveolar lavage. Am J Respir Crit Care Med 175: 222-227.

19. Montuschi $P$ (2007) Analysis of exhaled breath condensate in respiratory medicine: methodological aspects and potential clinical applications. Ther Adv Respir Dis 1: 5-23.

20. Montuschi P, Ragazzoni E, Valente S, Corbo G, Mondino C, et al. (2003) Validation of 8-isoprostane and prostaglandin $E(2)$ measurements in exhaled breath condensate. Inflamm Res 52: 502-507.

21. Szili B, Bikov A, Kollai M, Horvath I (2007) The $\mathrm{pH}$ of the exhaled breath condensate: new method for investigation of inflammatory airway diseases. Orv Hetil 148: 1217-1224. 
22. Rahman I (2004) Reproducibility of oxidative stress biomarkers in breath condensate: are they reliable? Eur Respir J 23: 183-184.

23. Gajdocsi R, Bikov A, Antus B, Horvath I, Barnes PJ, et al. (2011) Assessment of Reproducibility of Exhaled Hydrogen Peroxide Concentration and the Effect of Breathing Pattern in Healthy Subjects. J Aerosol Med Pulm Drug Deliv 24: 271-275.

24. Van Hoydonck PG, Wuyts WA, Vanaudenaerde BM, Schouten EG, Dupont LJ et al. (2004) Quantitative analysis of 8-isoprostane and hydrogen peroxide in exhaled breath condensate. Eur Respir J 23:189-192.

25. Janicka M, Kot-Wasik A, Kot J, Namiesnik J (2010) Isoprostanes-biomarkers of lipid peroxidation: their utility in evaluating oxidative stress and analysis. Int J Mol Sci 11: 4631-4659.

26. Hom S, Walsh B, Hunt J (2008) Matrix effect in exhaled breath condensate interferon-gamma immunoassay. J Breath Res 2: 041001.

27. Repine JE (1992) Scientific perspectives on adult respiratory distress syndrome. Lancet 339: 466-469.

28. Rubenfeld GD, Caldwell E, Peabody E, Weaver J, Martin DP, et al. (2005) Incidence and outcomes of acute lung injury. N Engl J Med 353: 1685-1693.

29. Zambon M, Vincent JL (2008) Mortality rates for patients with acute lung injury/ ARDS have decreased over time. Chest 133: 1120-1127.

30. Deitch EA, Goodman ER (1999) Prevention of multiple organ failure. Surg Clin North Am 79: 1471-1488.

31. Herridge MS (2002) Long-term outcomes after critical illness. Curr Opin Crit Care 8: 331-336

32. Herridge MS, Tansey CM, Matte A, Tomlinson G, Diaz-Granados N, et al (2011) Functional disability 5 years after acute respiratory distress syndrome. N Engl J Med 364: 1293-1304.

33. Calfee CS, Matthay MA (2007) Nonventilatory treatments for acute lung injury and ARDS. Chest 131: 913-920.

34. Levitt JE, Matthay MA (2006) Treatment of acute lung injury: historical perspective and potential future therapies. Semin Respir Crit Care Med 27 426-437.

35. Bernard GR, Wheeler AP, Arons MM, Morris PE, Paz HL, et al. (1997) A tria of antioxidants $\mathrm{N}$-acetylcysteine and procysteine in ARDS. The Antioxidant in ARDS Study Group. Chest 112: 164-172.

36. Abraham E, Bursten S, Shenkar R, Allbee J, Tuder R, et al. (1995) Phosphatidic acid signaling mediates lung cytokine expression and lung inflammatory injury after hemorrhage in mice. J Exp Med 181: 569-575.

37. Hybertson BM, Bursten SL, Leff JA, Lee YM, Jepson EK, et al. (1997) Lisofylline prevents leak, but not neutrophil accumulation, in lungs of rats given IL-1 intratracheally. J Appl Physiol 82: 226-232.

38. Ware LB (2005) Prognostic determinants of acute respiratory distress syndrome in adults: impact on clinical trial design. Crit Care Med 33: S217-222.

39. Gajic O, Dabbagh O, Park PK, Adesanya A, Chang SY, et al. (2011) Early identification of patients at risk of acute lung injury: evaluation of lung injury prediction score in a multicenter cohort study. Am J Respir Crit Care Med 183 $462-470$

40. Fudala R, Allen TC, Krupa A, Cagle PT, Nash S, et al. (2011) Increased levels of nuclear factor kappaB and Fos-related antigen 1 in lung tissues from patients with acute respiratory distress syndrome. Arch Pathol Lab Med 135: 647-654.

41. Sack U, Scheibe R, Wotzel M, Hammerschmidt S, Kuhn H, et al. (2006) Multiplex analysis of cytokines in exhaled breath condensate. Cytometry A 69: 169-172.

42. Baldwin SR, Simon RH, Grum CM, Ketai LH, Boxer LA, et al. (1986) Oxidant activity in expired breath of patients with adult respiratory distress syndrome. Lancet 1: 11-14

43. Repine JE, Fox RB, Berger EM (1981) Hydrogen peroxide kills Staphylococcus aureus by reacting with staphylococcal iron to form hydroxyl radical. J Bio Chem 256: 7094-7096.

44. Klebanoff SJ (1999) Myeloperoxidase. Proc Assoc Am Physicians 111: 383 389

45. Wilson WC, Swetland JF, Benumof JL, Laborde P, Taylor R (1992) General anesthesia and exhaled breath hydrogen peroxide. Anesthesiology 76: 703710.
46. Sznajder JI, Fraiman A, Hall JB, Sanders W, Schmidt G, et al. (1989) Increased hydrogen peroxide in the expired breath of patients with acute hypoxemic respiratory failure. Chest 96: 606-612.

47. Kietzmann D, Kahl R, Muller M, Burchardi H, Kettler D (1993) Hydrogen peroxide in expired breath condensate of patients with acute respiratory failure and with ARDS. Intensive Care Med 19: 78-81.

48. Bruhn A, Liberona L, Lisboa C, Borzone G (2005) Limitations of the technique to determine hydrogen peroxide levels in exhaled breath condensate from patients with adult respiratory distress syndrome. Arch Bronconeumol 41: 542 546

49. Brooks WM, Lash H, Kettle AJ, Epton MJ (2006) Optimising hydrogen peroxide measurement in exhaled breath condensate. Redox Rep 11: 78-84.

50. Svensson S, Olin AC, Larstad M, Ljungkvist G, Toren K (2004) Determination of hydrogen peroxide in exhaled breath condensate by flow injection analysis with fluorescence detection. J Chromatogr B Analyt Technol Biomed Life Sci 809: 199-203.

51. Stolarek R, Bialasiewicz P, Krol M, Nowak D (2010) Breath analysis of hydrogen peroxide as a diagnostic tool. Clin Chim Acta 411: 1849-1861.

52. Thebaud B, Arnal JF, Mercier JC, Dinh-Xuan AT (1999) Inhaled and exhaled nitric oxide. Cell Mol Life Sci 55: 1103-1112.

53. Hyde RW, Geigel EJ, Olszowka AJ, Krasney JA, Forster RE 2nd, et al. (1997) Determination of production of nitric oxide by lower airways of humans--theory. J Appl Physiol 82: 1290-1296.

54. Kovesi T, Szabo A, Royston D, Marczin N (2005) Correlation between pulmonary gas exchange and basal and nitroglycerin (GTN)-induced exhaled nitric oxide $(\mathrm{eNO})$ in patients undergoing cardiac surgery. Vascul Pharmacol 43: $434-440$

55. Gessner C, Hammerschmidt S, Kuhn H, Lange T, Engelmann L, et al. (2003) Exhaled breath condensate nitrite and its relation to tidal volume in acute lung injury. Chest 124: 1046-1052.

56. Sittipunt C, Steinberg KP, Ruzinski JT, Myles C, Zhu S, et al. (2001) Nitric oxide and nitrotyrosine in the lungs of patients with acute respiratory distress syndrome. Am J Respir Crit Care Med 163: 503-510.

57. Cuthbertson BH, Stott SA, Webster NR (2002) Exhaled nitric oxide as a marker of lung injury in coronary artery bypass surgery. Br J Anaesth 89: 247-250.

58. Brett SJ, Evans TW (1998) Measurement of endogenous nitric oxide in the lungs of patients with the acute respiratory distress syndrome. Am J Respir Crit Care Med 157: 993-997.

59. Gessner C, Hammerschmidt S, Kuhn H, Seyfarth HJ, Sack U, et al. (2003) Exhaled breath condensate acidification in acute lung injury. Respir Med 97 1188-1194.

60. Kostikas K, Papatheodorou G, Ganas K, Psathakis K, Panagou P, et al. (2002) $\mathrm{pH}$ in expired breath condensate of patients with inflammatory airway diseases. Am J Respir Crit Care Med 165: 1364-1370.

61. Bastin AJ, Sato H, Davidson SJ, Quinlan GJ, Griffiths MJ (2011) Biomarkers of lung injury after one-lung ventilation for lung resection. Respirology 16: 138145.

62. Korovesi I, Papadomichelakis E, Orfanos SE, Giamarellos-Bourboulis EJ, Livaditi O, et al. (2011) Exhaled breath condensate in mechanically ventilated brain-injured patients with no lung injury or sepsis. Anesthesiology 114: 11181129 .

63. Hunt J (2006) Airway acidification: interactions with nitrogen oxides and airway inflammation. Curr Allergy Asthma Rep 6: 47-52

64. Carpenter CT, Price PV, Christman BW (1998) Exhaled breath condensate isoprostanes are elevated in patients with acute lung injury or ARDS. Ches 114: 1653-1659.

65. Scholpp J, Schubert JK, Miekisch W, Geiger K (2002) Breath markers and soluble lipid peroxidation markers in critically ill patients. Clin Chem Lab Med 40: $587-594$

66. Miekisch W, Schubert JK, Vagts DA, Geiger K (2001) Analysis of volatile disease markers in blood. Clin Chem 47: 1053-1060.

67. Schubert JK, Miekisch W, Geiger K, Noldge-Schomburg GF (2004) Breath analysis in critically ill patients: potential and limitations. Expert Rev Mol Diagn 4: 619-629. 
68. Gessner C, Dihazi H, Brettschneider S, Hammerschmidt S, Kuhn H, et al. (2008) Presence of cytokeratins in exhaled breath condensate of mechanical ventilated patients. Respir Med 102: 299-306.

69. Repine JJ, Crader KM, Elkins ND, Wilson P, Repine JE (2011) Preventing the Acute Respiratory Distress Syndrome.

70. Heard SO, Longtine K, Toth I, Puyana JC, Potenza B, et al. (1999) The influence of liposome-encapsulated prostaglandin E1 on hydrogen peroxide concentrations in the exhaled breath of patients with the acute respiratory distress syndrome. Anesth Analg 89: 353-357.

71. Roca O, Gomez-Olles S, Cruz MJ, Munoz X, Griffiths MJ, et al. (2008) Effects of salbutamol on exhaled breath condensate biomarkers in acute lung injury: prospective analysis. Crit Care 12: R72.

72. Ortolani O, Conti A, De Gaudio AR, Masoni M, Novelli G (2000) Protective effects of $\mathrm{N}$-acetylcysteine and rutin on the lipid peroxidation of the lung epithelium during the adult respiratory distress syndrome. Shock 13: 14-18.

73. Popov TA (2011) Human exhaled breath analysis. Ann Allergy Asthma Immuno 106: $451-456$.

74. Sofia M, Maniscalco M, de Laurentiis G, Paris D, Melck D, et al. (2011) Exploring airway diseases by NMR-based metabonomics: a review of application to exhaled breath condensate. J Biomed Biotechnol 2011: 403260.

75. de Laurentiis G, Paris D, Melck D, Maniscalco M, Marsico S, et al. (2008) Metabonomic analysis of exhaled breath condensate in adults by nuclear magnetic resonance spectroscopy. Eur Respir J 32: 1175-1183.

76. Lacy P (2011) Metabolomics of sepsis-induced acute lung injury: a new approach for biomarkers. Am J Physiol Lung Cell Mol Physiol 300: L1-3.

77. Montuschi $P$ (2009) LC/MS/MS analysis of leukotriene B4 and other eicosanoids in exhaled breath condensate for assessing lung inflammation. J Chromatogr $B$ Analyt Technol Biomed Life Sci 877: 1272-1280.

78. Filipiak W, Sponring A, Filipiak A, Ager C, Schubert J, et al. (2010) TD-GC-MS analysis of volatile metabolites of human lung cancer and normal cells in vitro. Cancer Epidemiol Biomarkers Prev 19: 182-195.

79. Bartolome J, Penuelas J, Filella I, Llusia J, Broncano MJ, et al. (2007) Mass scans from a proton transfer mass spectrometry analysis of air ove Mediterranean shrubland browsed by horses. J Environ Biol 28: 697-700.

80. Vlasenko A, Macdonald AM, Sjostedt SJ, Abbatt JPD (2010) Formaldehyde measurements by Proton transfer reaction - Mass Spectrometry (PTR-MS): correction for humidity effects. Atmos Meas Tech 3: 1055-1062.

81. Peng G, Hakim M, Broza YY, Billan S, Abdah-Bortnyak R, et al. (2010) Detection of lung, breast, colorectal, and prostate cancers from exhaled breath using a single array of nanosensors. Br J Cancer 103: 542-551.

82. Gold L, Ayers D, Bertino J, Bock C, Bock A, et al. (2010) Aptamer-based multiplexed proteomic technology for biomarker discovery. PLoS ONE 5: e15004.

83. Conrad DH, Goyette J, Thomas PS (2008) Proteomics as a method for early detection of cancer: a review of proteomics, exhaled breath condensate, and lung cancer screening. J Gen Intern Med 23: 78-84.

84. Thorpe MJ, Balslev-Clausen D, Kirchner MS, Ye J (2008) Cavity-enhanced optical frequency comb spectroscopy: application to human breath analysis. Opt Express 16: 2387-2397.

85. Weigand MA, Snyder-Ramos SA, Mollers AG, Bauer J, Hansen D, et al. (2000) Inhaled nitric oxide does not enhance lipid peroxidation in patients with acute respiratory distress syndrome. Crit Care Med 28: 3429-3435.

86. Miekisch W, Kischkel S, Sawacki A, Liebau T, Mieth M, et al. (2008) Impact of sampling procedures on the results of breath analysis. J Breath Res 2: 026007.

87. Schubert JK, Miekisch W, Birken T, Geiger K, Noldge-Schomburg GF (2005) Impact of inspired substance concentrations on the results of breath analysis in mechanically ventilated patients. Biomarkers 10: 138-152.

88. Bartoli ML, Novelli F, Costa F, Malagrino L, Melosini L, et al. (2011) Malondialdehyde in exhaled breath condensate as a marker of oxidative stress in different pulmonary diseases. Mediators Inflamm 2011: 891752

89. Mumby S, Chung KF, McCreanor JE, Moloney ED, Griffiths MJ, et al. (2011) Pro-oxidant iron in exhaled breath condensate: A potential excretory mechanism. Respir Med 105: 1290-1295.
90. Folesani G, Corradi M, Goldoni M, Manini P, Acampa O, et al. (2008) Urea in exhaled breath condensate of uraemics and patients with chronic airway diseases. Acta Biomed 1: 79-86.

91. Simpson JL, Wood LG, Gibson PG (2005) Inflammatory mediators in exhaled breath, induced sputum and saliva. Clin Exp Allergy 35: 1180-1185.

92. Chan HP, Tran V, Lewis C, Thomas PS (2009) Elevated levels of oxidative stress markers in exhaled breath condensate. J Thorac Oncol 4: 172-178.

93. Garey KW, Neuhauser MM, Robbins RA, Danziger LH, Rubinstein I (2004) Markers of inflammation in exhaled breath condensate of young healthy smokers. Chest 125: 22-26.

94. Marek E, Platen P, Volke J, Muckenhoff K, Marek W (2009) Hydrogen peroxide release and acid-base status in exhaled breath condensate at rest and afte maximal exercise in young, healthy subjects. Eur J Med Res 14: 134-139.

95. Marek E, Muckenhoff K, Streckert HJ, Becher G, Marek W (2008) Measurements of L-lactate and $\mathrm{H} 2 \mathrm{O} 2$ in exhaled breath condensate at rest and mild to moderate exercise in young and healthy subjects. Pneumologie 62: $541-547$

96. Horvath I, MacNee W, Kelly FJ, Dekhuiizen PN, Phillips M, et al. (2001) "Haemoxygenase-1 induction and exhaled markers of oxidative stress in lung diseases", summary of the ERS Research Seminar in Budapest, Hungary, September, 1999. Eur Respir J 18: 420-430

97. Chapman JT, Choi AM (2001) Exhaled monoxides as a pulmonary function test: use of exhaled nitric oxide and carbon monoxide. Clin Chest Med 22 817-836.

98. Gajdocsy R, Horvath I (2010) Exhaled carbon monoxide in airway diseases: from research findings to clinical relevance. J Breath Res 4: 047102.

99. Zhang J, Yao X, Yu R, Bai J, Sun Y, et al. (2010) Exhaled carbon monoxide in asthmatics: a meta-analysis. Respir Res 11: 50.

100. Rahman I, Biswas SK (2004) Non-invasive biomarkers of oxidative stress: reproducibility and methodological issues. Redox Rep 9: 125-143.

101. Kharitonov SA, Barnes PJ (2002) Biomarkers of some pulmonary diseases in exhaled breath. Biomarkers 7: 1-32.

102. Skiepko R, Zietkowski Z, Tomasiak MM, Bodzenta-Lukaszyk A (2006) Exhaled breath condensate in the assessment of airway inflammation. Przegl Lek 63 $1321-1325$

103. Effros RM (2004) Re: Repeatability of sodium and chloride in exhaled breath condensates, Zacharasiewicz et al. Pediatr Pulmonol 2004;37:273-275 Pediatr Pulmonol 38: 358-359.

104.Zakharkina T, Koczulla AR, Mardanova O, Hattesohl A, Bals R (2011) Detection of microorganisms in exhaled breath condensate during acute exacerbations of COPD. Respirology 16: 932-938.

105. Houspie L, De Coster S, Keyaerts E, Narongsack P, De Roy R, et al. (2011) Exhaled breath condensate sampling is not a new method for detection of respiratory viruses. Virol J 8: 98

106. Ayer HE, Willeke K (1988) Particle concentration in exhaled breath. Am Ind Hyg Assoc J 49: A156, A158.

107. Suter PM, Suter S, Girardin E, Roux-Lombard P, Grau GE, et al. (1992) High bronchoalveolar levels of tumor necrosis factor and its inhibitors, interleukin-1, interferon, and elastase, in patients with adult respiratory distress syndrome after trauma, shock, or sepsis. Am Rev Respir Dis 145: 1016-1022.

108. Pugin J, Ricou B, Steinberg KP, Suter PM, Martin TR (1996) Proinflammatory activity in bronchoalveolar lavage fluids from patients with ARDS, a prominent role for interleukin-1. Am J Respir Crit Care Med 153: 1850-1856.

109. Routsi C, Bardouniotou H, Delivoria-loannidou V, Kazi D, Roussos C, et al. (1999) Pulmonary lactate release in patients with acute lung injury is not attributable to lung tissue hypoxia. Crit Care Med 27: 2469-2473.

110. Stapleton RD, Martin TR, Weiss NS, Crowley JJ, Gundel SJ, et al. (2011) A phase II randomized placebo-controlled trial of omega-3 fatty acids for the treatment of acute lung injury. Crit Care Med 39: 1655-1662.

111. Koutsokera A, Loukides S, Gourgoulianis KI, Kostikas K (2008) Biomarkers in the exhaled breath condensate of healthy adults: mapping the path towards reference values. Curr Med Chem 15: 620-630 
Citation: Crader KM, Repine JJD, Repine JE (2012) Breath Biomarkers and the Acute Respiratory Distress Syndrome. J Pulmonar Respirat Med 2:111. doi:10.4172/2161-105X.1000111

Page 9 of 9

112. Fremont RD, Koyama T, Calfee CS, Wu W, Dossett LA, et al. (2010) Acute lung injury in patients with traumatic injuries: utility of a panel of biomarkers for diagnosis and pathogenesis. J Trauma 68: 1121-1127.

113. Risby TH, Sehnert SS (1999) Clinical application of breath biomarkers of oxidative stress status. Free Radic Biol Med 27: 1182-1192.
114. Owens RL, Stigler WS, Hess DR (2008) Do newer monitors of exhaled gases, mechanics, and esophageal pressure add value? Clin Chest Med 29: 297-312

115. Moloney ED, Mumby SE, Gajdocsi R, Cranshaw JH, Kharitonov SA, et al (2004) Exhaled breath condensate detects markers of pulmonary inflammation after cardiothoracic surgery. Am J Respir Crit Care Med 169: 64-69. 